\title{
Capping and Mitogenesis: A Model Implicating Microfilaments in Lymphocyte Activation
}

\author{
K. Murali Krishna Rao \\ Department of Pathology, The University of Michigan, Ann Arbor, \\ Michigan 48109, U.S.A.*
}

(Received 31 August 1981, and in revised form 5 March 1982)

\begin{abstract}
In lymphocytes cap formation induced by concanavalin $A$ (con $A$ ) was found to be concentration dependent on the mitogen in the presence of colchicine, a microtubule disrupting agent. The dose-respone of cap formation under these conditions was similar to mitogen dose-response. In addition, a direct correlation was found between con $\mathrm{A}$ capping induced in the presence of colchicine and mitogenic responses with con $\mathrm{A}$ alone. Agents such as dibutyryl cyclic AMP, which suppress mitogenic responses, decrease capping. Zinc increases capping when it causes enhancement of mitogenesis and decreases capping when it suppresses mitogenic response. These observations are interpreted on the basis of a model in which binding of con A to surface receptors leads to formation of microfilaments, which might be essential for capping as well as the initiation of DNA synthesis. Thus, the experimental observations in this report lend support to a model implicating the formation of microfilaments as a crucial event in triggering a variety of cellular responses following ligand binding.
\end{abstract}

\section{Introduction}

Interaction of ligands with surface receptors of lymphocytes leads to rapid changes in the surface membrane and polarization of receptors leading to what is termed "cap" formation. Treatment of human peripheral blood lymphocytes (PBL) with fluoresceinated concanavalin $A(F-c o n ~ A)$ at $37^{\circ} \mathrm{C}$ induces cap formation in a small percentage of lymphocytes. Cap formation can be affected by cytoskeletal modulating agents such as colchicine (de Petris, 1974; Albertini, Berlin \& Oliver, 1977), cytochalasin B (de Petris, 1974; Yahara \& Edelman, 1975) and lidocaine (Poste, Papahadjopoulos \& Nicolson, 1975). The above observations suggest that the cell surface receptors interact with microtubules and microfilaments and disruption of these elements lead to alterations in surface receptor mobility (Yahara \& Edelman, 1975). Further, it is proposed that mitogenic stimulation of lymphocytes might involve formation of microaggregates of receptors on

* Current address: Clinical Chemistry Laboratory, 203 De Soto St., University of Pittsburgh, Pittsburgh, Pennsylvania 15261, U.S.A. 
the surface and the propagation of the signal into the cytoplasm and the nucleus of the cell through cytoskeletal structures (Edelman, 1974).

In order to study the relationship between the con A-induced capping and con $\mathrm{A}$-induced mitogenic responses, experiments were done to examine capping and mitogenic responses with the same preparation of con A simultaneously, in the presence of various drugs. Our data indicate that the con A-induced capping in the presence of colchicine demonstrates a direct correlation with mitogenic responses induced by con $\mathrm{A}$ alone. Further, it is demonstrated that agents which enhance mitogenic responses increase capping and agents which suppress mitogenic responses decrease capping. On the basis of these observations a model is presented to explain the relationship between capping and mitogenic responses.

\section{Materials and Methods}

Donors. Blood from young, healthy volunteers was freshly obtained from a peripheral vein. All donors gave informed consent consistent with the regulations of The University of Michigan and Department of Health and Human Services. The donor population ranged in age between 22-35 years.

Isolation of Mononuclear Cells. Mononuclear cells were prepared from fresh heparinized blood $(20 \mathrm{U} / \mathrm{ml})$ by Ficoll-Hypaque density gradient technique. The cells were washed three times with $\mathrm{Ca}^{2+}$ and $\mathrm{Mg}^{2+}$ free Hanks' balanced salt solution (HBSS, Grand Island Biological Co., Grand Island, N.Y.) and resuspended in RPMI 1640 medium (Grand Island Biological Co.).

Chemicals. Colchicine and $\mathrm{N}^{6}, \mathrm{O}^{2 \prime}$-dibutyryl adenosine $3^{\prime}: 5^{\prime}$ cyclic monophosphoric acid (DbcAMP) were obtained from Sigma Chemical Co., St. Louis, Missouri. $\mathrm{ZnCl}_{2}$ was obtained from Fisher Scientific Co., New Jersey. F-con A was obtained from Calbiochem-Behring Corporation, LaJolla, California. It had a fluorescein/protein ratio (molar) of $5 \cdot 7$. Methyl$\left[{ }^{3} \mathrm{H}\right]$ Thymidine $\left(\left[{ }^{3} \mathrm{H}\right]\right.$ Thymidine $)$, specific activity $6.7 \mathrm{ci} / \mathrm{mmol}$ was obtained from New England Nuclear, Boston, Massachusetts.

\section{MITOGENIC EXPERIMENTS}

Cells were cultured in 96 well round bottom microtiter plates at a concentration of 50000 cells in $100 \mu \mathrm{l}$ of culture medium. The culture medium consisted of $10 \%$ heat inactivated fetal calf serum, $2 \mu \mathrm{M}$ fresh glutamine and $50 \mu \mathrm{g}$ gentamicin per $\mathrm{ml}$ (Schering Corp., Kenilworth, New Jersey) in RPMI 1640. F-con A and drugs were added directly to the wells and the final volume was adjusted to $120 \mu \mathrm{l}$. The cells were incubated for 
$72 \mathrm{hr}$ at $37^{\circ} \mathrm{C}$ in an atmosphere consisting of $5 \% \mathrm{CO}_{2}$ and $95 \%$ air. At the end of $72 \mathrm{hr}, 2 \mu \mathrm{Ci}$ of $\left[{ }^{3} \mathrm{H}\right]$ Thymidine was added to each well and incubated for an additional $18 \mathrm{hr}$. The cells were harvested with an automatic cell harvester (Flow Laboratories, Rockville, Maryland) and $\left[{ }^{3} \mathrm{H}\right]$ Thymidine incorporation was measured by liquid scintillation counting. Cultures were set-up in triplicate and the data were expressed as mean \pm SEM.

\section{CAPPING EXPERIMENTS}

Mononuclear cells were suspended at a concentration of $4-6 \times 10^{6}$ cells $/ \mathrm{ml}$ in RPMI 1640 and $0.5 \mathrm{ml}$ of the suspension was used for each experiment. Drugs were added to the cells and incubated for 30 minutes at $37^{\circ} \mathrm{C}$ with continuous rotation. Then $\mathrm{F}$-con $\mathrm{A}$ was added and incubated for another 30 minutes. At the end of incubation the cells were fixed with $0.5 \mathrm{ml}$ of $2 \%$ paraformaldehyde for 10 minutes, washed twice with HBSS and the number of caps formed was enumerated under fluorescence microscopy. One hundred fluorescent labelled cells were counted and the number of caps was expressed as a percentage of a total of one hundred cells including the caps. The tubes were coded and read blindly to avoid observer bias.

\section{Results \\ EFFECTS OF COLCHICINE ON CAPPING}

Table I shows the number of caps formed at various concentrations of con $\mathrm{A}$ with and without colchicine $\left(10^{-5} \mathrm{M}\right.$, final concentration). The number of caps formed with con $\mathrm{A}$ alone is small and it is difficult to attribute any significance to the small differences noted. But in the presence of colchicine the numbers of caps are increased and a distinct concentration effect becomes evident. Further, the dose-response of the capping appears

TABLE 1

Effect of con $A$ concentration on capping with and without colchicine

\begin{tabular}{ccc}
\hline $\begin{array}{c}\text { Con } \mathbf{A} \\
(\mu \mathrm{g} / \mathbf{m})\end{array}$ & No colchicine & $\begin{array}{c}\text { Caps }(\%) \\
\text { Colchicine }\left(10^{-5} \mathbf{M}\right)\end{array}$ \\
\hline 30 & 6 & 30 \\
20 & 5 & 28 \\
10 & 8 & 42 \\
5 & 6 & 22 \\
\hline
\end{tabular}


remarkably similar to the mitogen dose-response curves. This observation prompted me to perform dose-responses of con A-induced capping with colchicine and compare it with mitogenic responses with con $\mathrm{A}$ alone. F-con A was used for both capping as well as mitogenic experiments.

\section{CORRELATION BETWEEN COLCHICINE INDUCED CAPPING \\ AND MITOGENIC RESPONSES}

Figure 1 shows the correlation between con A capping induced in the presence of colchicine and the mitogenic responses using the same concentrations of F-con A. A direct correlation between the number of caps formed and the mitogenic responses is evident.

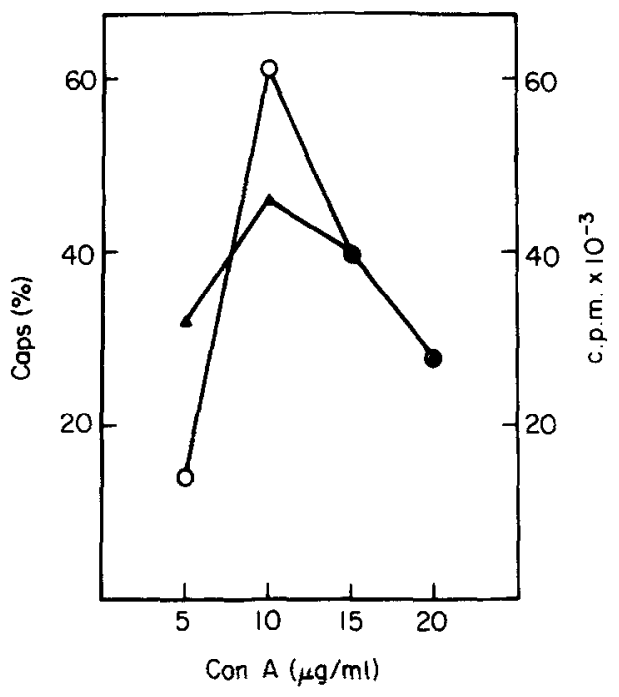

FIG. 1. Correlation between con A-capping induced in the presence of colchicine and mitogenic responses induced by con $\mathrm{A}$ alone. $\boldsymbol{\Delta}=$ caps $(\%) ; O=$ c.p.m. $\times 10^{-3}$.

EFFECTS OF DbCAMP ON CAPPING AND MITOGFNIC RFSPONSES

Table 2 shows two representative experiments with DbcAMP $\left(10^{-4} \mathrm{M}\right.$, final concentration). Capping experiments were performed with colchicine and colchicine plus DbcAMP. Cap formation was correlated with con A-induced mitogenic responses with and without DbcAMP. In both experiments suppression of capping was associated with suppression in mitogenic responses. 
TABLE 2

Effects of dibutyryl cyclic AMP on capping and mitogenic responses induced by $\operatorname{con} A$

\begin{tabular}{|c|c|c|c|c|}
\hline \multirow[b]{2}{*}{$\begin{array}{c}\text { Con A } \\
(\mu \mathrm{g} / \mathrm{ml})\end{array}$} & \multicolumn{2}{|c|}{ Caps $(\%)$} & \multicolumn{2}{|c|}{$\left[{ }^{3} \mathrm{H}\right]-$ Thymidine incorporation (c.p.m.) } \\
\hline & No Dbc A & Dbc AMP & No Dbc AMP & 1) $\mathrm{Dbc} M P$ \\
\hline \multicolumn{5}{|l|}{ Experiment 1} \\
\hline 30 & 32 & 29 & $26422 \pm 5160^{\dagger}$ & $5465 \pm 432$ \\
\hline 20 & 40 & 32 & $57152 \pm$ & $15841 \pm 944$ \\
\hline 15 & 43 & 32 & $75387 \pm 4696$ & $17599 \pm 1420$ \\
\hline 10 & 34 & 27 & $64887 \pm 10471$ & $14232 \pm 1904$ \\
\hline \multicolumn{5}{|l|}{ Experiment 2} \\
\hline 20 & 52 & 39 & $59313 \pm$ & $13696 \pm 289$ \\
\hline 15 & 44 & 38 & $38590 \pm$ & $15336 \pm 1465$ \\
\hline 10 & 46 & 42 & $27643 \pm$ & $15624 \pm 1574$ \\
\hline
\end{tabular}

+ Mean \pm SEM of triplicates.

EFFECTS OF ZINC ON CAPPING AND MITOGENIC RESPONSES

In contrast to DbcAMP which affects capping and mitogenic responses in a similar fashion at all concentrations of the mitogen tested, the zinc effect is concentration dependent on the mitogen. Therefore, a reasonable way to correlate capping and mitogenic data in this case would be to compare the maximum number of caps formed with and without zinc to maximal mitogenic response with and without zinc, ignoring the concentration of the mitogen at which these responses occur. Employing such a criterion it can be seen from Table 3 that in experiment 1 zinc $\left(10^{-4} \mathrm{M}\right.$,

\section{TABLE 3}

Effects of zinc on capping and mitogenic responses induced by con $A$

\begin{tabular}{|c|c|c|c|c|c|}
\hline \multirow[b]{2}{*}{$\begin{array}{c}\text { Con A } \\
(\mu \mathrm{g} / \mathrm{ml})\end{array}$} & \multicolumn{2}{|c|}{ Caps $(\%)$} & \multicolumn{3}{|c|}{$\left[{ }^{3} \mathrm{H}\right]-$ Thymidine incorporation (c.p.m.) } \\
\hline & No Zinc & Zinc & No Zinc & Zinc & \\
\hline \multicolumn{6}{|l|}{ Experiment 1} \\
\hline 20 & 52 & 51 & $59313 \pm 1659^{a}$ & $75296 \pm 2$ & 0325 \\
\hline 15 & 44 & 55 & $38590 \pm 4801$ & $79299 \pm 1$ & 2258 \\
\hline 10 & 46 & 41 & $27643 \pm 5219$ & $42942 \pm$ & 4739 \\
\hline \multicolumn{6}{|l|}{ Experiment 2} \\
\hline 20 & 56 & 47 & $33908 \pm 2388$ & $27498 \pm$ & 1103 \\
\hline 15 & 45 & 42 & $27991 \pm 2257$ & $15947 \pm$ & 1099 \\
\hline 10 & 43 & 43 & $25074 \pm 2309$ & $18020 \pm$ & 3769 \\
\hline
\end{tabular}

\footnotetext{
${ }^{\mathrm{a}}$ Mean \pm SEM of triplicates
} 
final concentration) causes an increase in the number of caps and there is a corresponding increase in the mitogenic response and in experiment 2 there is a decrease in the number of caps and there is a corresponding decrease in the mitogenic response.

\section{Discussion}

This study was undertaken to examine if the changes associated with lectin binding to surface receptors, such as capping, have any relationship to the mitogenic responses induced by these agents. It is well established that pretreatment of lymphocytes with colchicine, a microtubule disrupting agent, enhances con A-induced capping (de Petris, 1974; Albertini et al, 1977). This has been interpreted to mean that microtubules have an anchoring effect on the surface receptors and prevent their mobility. Pretreatment of lymphocytes with cytochalasin B, on the other hand, prevents cap formation indicating that the microfilament function is essential for cap formation (de Petris, 1974; Yahara \& Edelman, 1975). Colchicine and cytochalasin B can also modify con A-induced mitogenic responses (Yahara \& Edelman, 1975; Medrano, Piras \& Mordoh, 1974). It was proposed that mitogenic stimulation of lymphocytes might involve formation of microaggregates of receptors on the surface and propagation of the signal into the cytoplasm and the nucleus of the cell through cytoskeletal structures (Edelman, 1974). In this report, evidence is presented that, under certain conditions, there is a direct correlation between capping and mitogenic responses. Advantage was taken of the fact that colchicine enhances capping and that in the presence of this drug capping becomes a con A-concentration dependent phenomenon.

Exogenous cAMP has been shown to suppress mitogenic responses induced by lectins (Smith, Steiner \& Parker, 1971). The experiments indicate that Dbc AMP, in the presence of colchicine, can also suppress capping. It was shown that in the amoeba, Dictyostelium discoideum, plasma membrane fragments contain a large amount of actin and myosin following con A binding. The author concludes that the ATP-dependent sliding of membrane associated actin and myosin filaments may be responsible for the accumulation of con A receptor complexes into a cap on the cell surface (Condeelis, 1979). ATP plays an important role in the polymerization of actin (Lin et al., 1980); nascent actin chains are shown to be substrates for cyclic AMP-dependent phosphorylation (Steinberg, 1980). Mitogenic stimulation of lymphocytes activates cyclic AMP-dependent protein kinase (Klimpel et al. 1979), and phosphorylation of a number of proteins takes placc within minutes following the mitogenic stimulation (Chaplin, Wedner 
\& Parker, 1980). It has been shown that phosphorylated platelet myosin has higher actin activation than unphosphorylated myosin (Adelstein \& Conti, 1975). Similarly phosphorylation of the $20000 \mathrm{~m}$.w. light chain of gizzard myosin is required for optimal actin activation (Gorecka, Askoy \& Hartshorne, 1976; Askoy et al., 1976). These observations suggest a close interaction between cyclic AMP, actin microfilament formation and mitogenic responses.

The effects of zinc on capping and mitogenic responses induced by con $A$ are also of great interest. Zinc has variable effects on mitogenic responses, causing enhancement in some cases and suppression in others (Rao, Schwartz \& Good, 1979). Previous studies indicate that the site of action of zinc is likely to be microfilaments and that zinc does not have an effect on colchicine sensitive structures (Rao \& Schwartz, 1980). In the present experiments with zinc, enhancement of capping was associated with enhanced mitogenic responses and decrease in the capping was associated with suppressed mitogenic responses. Thus, it appears that mitogenic responses of lymphocytes are directly related to the capping process, induced in the presence of colchicine.

However, it should be noted that the correlation between the capping and the mitogenic responses is artificial. The conditions under which capping and mitogenic responses performed are different. Colchicine was not present in mitogenic experiments, because at a concentration of $10^{-5} \mathrm{M}$, colchicine completely inhibits mitogenic responses (Medrano et al, 1974; Rao \& Schwartz, 1980). However, the model proposed below attempts to offer a rationale for these experimental observations and explain the relationship between capping and mitogenic responses induced by con $\mathrm{A}$.

It is known that filamentous structures can form rapidly and transiently; the contractile ring during mitosis forms shortly before mitosis and disappears afterwards (Schroeder, 1972). Microfilament bundles form rapidly during spreading of fibroblasts and disappear in rounded cells (Goldman, 1975; Goldman \& Knipe, 1973). It has been shown that following reduction of microvilli of the small intestine of the salamander, the first step in their re-formation was accumulation of a dense material on the cytoplasmic surface and filaments then extend from this dense region (Tilney \& Cardell, 1970). Thus, the interaction of microfilaments with the cell membrane appears to be a dynamic process. Actin is a major component of microfilaments and the dynamic state of microfilament formation implies that actin can rapidly dissociate and associate and that it can exist in a state of equilibrium between monomeric and the polymeric state.

In the present model (Fig. 2) I propose a portion of the actin exists in a soluble state in unstimulated lymphocytes. When a lectin binds to a surface 

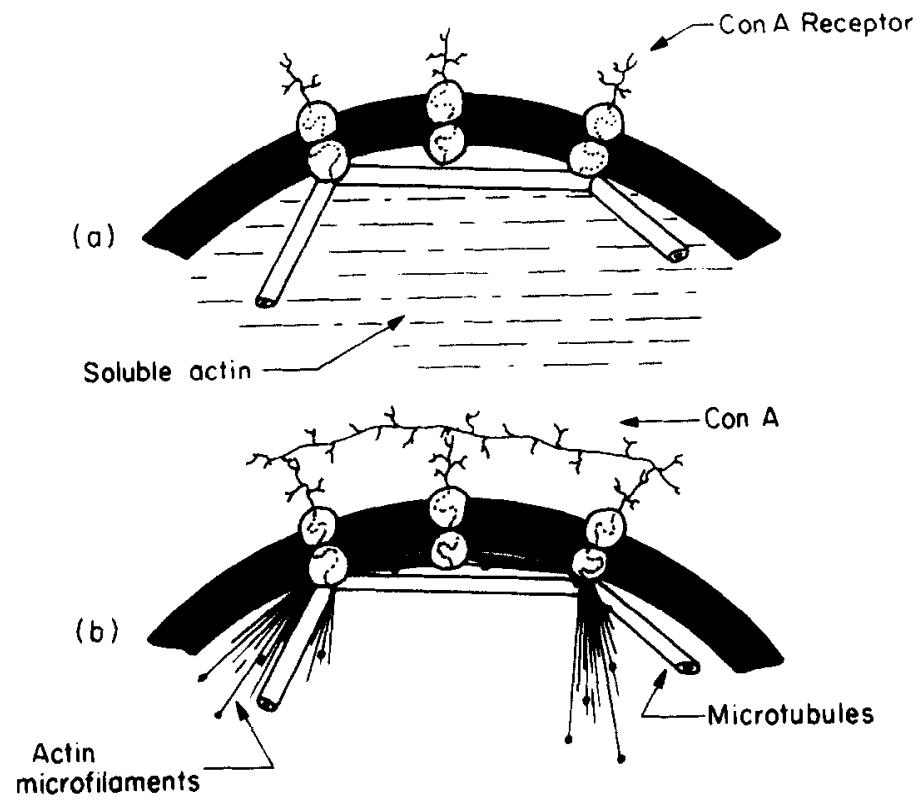

microfilaments

c)

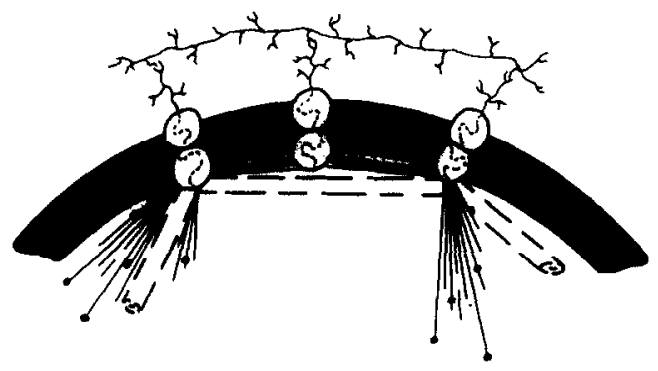

(d)

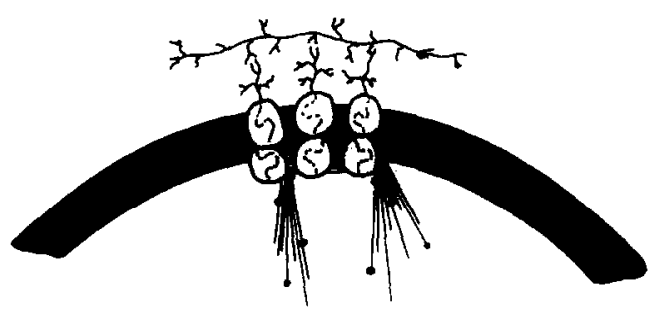

FIG. 2. A model to explain the relationship between con A-capping induced in the presence of colchicine and con A-induced mitogenic responses. (a) The fluid mosaic model of membrane structure with con A receptors anchored to microtubules. In unstimulated lymphocyte a portion of actin exists in soluble state. Binding of con A induces a conformational change in the receptor and the base of the receptor becomes a nucleus for actin polymerization and microfilament formation. (b) Polymerization of actin leads to events which finally result in 
receptor it induces a conformational change in the receptor and the base of the receptor becomes a focal point for actin attachment and microfilament formation. The fact that only cross linked surface immunoglobulin is found attached to actin but not uncrosslinked surface immunoglobulin (Flanagan \& Koch, 1978) indicates that attachment of actin to surface molecules occurs following ligand binding. The process of microfilament formation appears to trigger DNA synthesis. Support for the involvement of microfilaments in DNA synthesis comes from the fact that cytochalasin B can modulate DNA synthesis induced by lectins (Hoffman, Ferguson \& Simmons, 1977; Greene, Parker \& Parker, 1976). The formation of microfilaments can also lead to a variety of other biological effects, one of the effects being cap formation. But treatment of lymphocytes with con A alone does not cause capping (capping occurs only in a small percentage of human peripheral blood lymphocytes) because the receptor movement is restrained by microtubules. However, if microtubules are disrupted by colchicine, formation of microfilaments freely proceeds to cap formation; under these conditions capping becomes roughly proportional to microfilament formation. Thus, the use of colchicine in capping experiments is a tool for unmasking the microfilament formation that occurs following lectin binding. According to this model the crucial element that is required for DNA synthesis is microfilament formation; capping is only an epiphenomenon as far as DNA synthesis is concerned. But under appropriate conditions (i.e., in the presence of colchicine) capping becomes a measure of microfilament formation and can be correlated with mitogenic responses. Thus, capping and mitogenic responses may be a reflection of the same event occurring in the cell, namely the microfilament formation.

Attempts were made in the past to correlate capping and lymphocyte triggering (Loor, 1977) and the general concensus has been that capping is unrelated to lymphocyte triggering. This study essentially reaches the same conclusion that capping is not related to mitogenesis as a cause and effect phenomenon. But in as much as both capping and mitogenic responses depend upon microfilament formation (according to the model) a correlation can be shown under certain conditions. The fact that the cells which had bound and capped PHA and con A fail to undergo mitogenesis when they were cultured in the absence of lectins was considered as an indication that capping is irrelevant to the mitogenic process (Loor, 1974). But if one

DNA synthesis. Formation of microfilaments can also bring about capping provided the anchoring effect of microtubules is removed. Treatment of lymphocytes with colchicine prior to con A treatment disrupts microtubules. (c). Under these conditions formation of microfilaments proceeds to cap formation. (d). In the presence of colchicine, capping becomes roughly proportional to microfilament formation and can be correlated with mitogenic responses. 
considers the microfilament formation as the crucial event in the inititation of DNA synthesis; the formation of microfilaments being a reversible, dynamic event, sustained presence of a lectin in the medium might be necessary to keep the actin in a polymerized state (microfilaments) to initiate DNA synthesis.

A model similar to this one based on the assembly of microfilaments following ligand-receptor interaction has been proposed to explain the stimulus induced secretion in neutrophils (Hoffstein, Korchak \& Smolen, 1981). These models receive strong support from the recent demonstration that actin polymerization accompanies thy-1-capping on mouse lymphocytes (Laub, Kaplan \& Gitler, 1981).

Although the model presented is based on the interaction of ligands with lymphocyte receptors, the ubiquitous presence of microfilaments in eukaryotic cells may make this model applicable to interaction of a variety of molecules such as peptide hormones, lymphokines and interferon with different cell types.

I thank James M. Vogt for technical assistance. Supported by The Biomedical Research Support Grant No. 018123 of The University of Michigan.

\section{REFERENCES}

Adelstein, R. S. \& CONTI, M. A. (1975). Nature Lond. 256, 597.

Albertini, D. F., Berlin, R. D. \& Oliver, J. M. (1977). J. Cell Sci. 269, 57.

Askoy, M. O., Williams, D., Sharkey, E. M. \& Hartshorne, D. J. (1976). Biochem. biophys. Res. Commun. 69, 1935.

Chaplin, D. D. Wedner, H. J. \& PARkeR, C. W. (1980). J. Immun. 124, 2390.

CONDEELIS, J. (1979). J. Cell Biol. 80, 751.

DE PETRIS, S. (1974). Nature 250, 54.

Edelman, G. M. (1974). In: Control of Proliferation in Animal Cells. (Clarkson, B. and Baserga, R. eds) New York: Cold Spring Harbor Laboratory. p. 357.

Flanagan, J. \& KoCH, G. L. E. (1978). Nature 273, 278.

Goldman, R. D. (1975). J. Histochem. Cytochem. 23, 529.

Goldman, R. D. \& KNIPE, D. M. (1973). Cold Spring Harbor Symp. Quant. Biol. 37, 523.

Górecka, A., Askoy, M. O. \& HARTShORNe, D. J. (1976). Biochem. biophys. Res. Commun. 71, 325.

Greene, W. C., Parker, C. M. \& Parker, C. H. W. (1976). Exp. Cell Res. 103, 109.

Hoffman, R., Ferguson, R. \& Simmons, R. L. (1977). J. Immun. 118, 1472.

Hoffstein, S. T., Korchak, H. M. \& SMOLen, J. E. (1981). Fed. Proc. $40,209$.

Klimpel, G. R., Byus, C. V., Russell, D. H. \& LuCAS, D. O. (1979). J. Immun. 123, 817.

LAUB, F., KAPLAN, M. \& Gitler, C. (1981). FEBS Lett. 124, 35.

Lin, D. C., TOBIN, K. D., Grumet, M. \& Lin, S. (1980). J. Cell Biol. 84, 455.

LOOR, F. (1974). Eur. J. Immun. 4, 210.

LOOR, F. (1977), Prog. Allergy 23, 1.

Medrano, E., Piras, R. \& Mordoh, J. (1974). Exp. Cell Res. 86, 295.

Poste, G., Papahadjopoulos, D. \& Nicolson, G. L. (1975). Proc. natn. Acad. Sci. U.S.A. 72, 4430. 
RAO, K. M. K. \& SChwartz, S. A. (1980). Clin. Immunol. Immunopath. 16, 463.

RAO, K. M. K., SCHWARTZ, S. A. \& Good, R. A. (1979). Cell Immun. 42, 270.

SCHROEDER, T. E. (1972). J. Cell Biol. 53, 419.

SMITH, J. W., STEINer, A. L. \& PARKeR, C. W. (1971). J. clin. Invest. 50, 442.

Steingerg, R. A. (1980). Proc. natn. Acad. Sci. U.S.A. 77, 910.

Tileny, L. G. \& CARDEl.l, R. R., JR. (1970). J. Cell Biol. 47, 408.

YAHARA, I. \& EdElman, G. M. (1973). Nature 246, 152. 